\title{
Como a percepção das ferramentas de análise de risco facilitam o processo de decisão em ambiente industrial
}

\author{
Janice Beatriz Machado ${ }^{1}$; Leandro de Oliveira ${ }^{2}$; \\ 1,2 Universidade de Uberaba \\ jani_beatriz@hotmail.com; \\ leandro.oliveira@uniube.br
}

\section{1 - Introdução}

A Resolução 001-86 do Conselho Nacional do Meio Ambiente (CONAMA) informa que "impacto ambiental é qualquer alteração das propriedades físicas, químicas e biológicas do meio ambiente, causada por qualquer forma de matéria ou energia resultante das atividades humanas que, direta ou indiretamente, afetam: a saúde, a segurança e o bem - estar da população; as atividades sociais e econômicas; a biota; as condições estéticas e sanitárias do meio ambiente; e a qualidade dos recursos ambientais". (BRASIL, 2012).

Desse modo, deduz-se que a contaminação do ar, das águas, do solo e subsolo, dos alimentos, a poluição sonora, a deterioração da paisagem, o desequilíbrio ecológico, entre outros, são consequências de atividades humanas conduzidas de forma irresponsável e sem compromisso que acabam por destruir os recursos naturais e põem em risco a vida humana. (PINHEIRO, 1993).

Acidentes com materiais perigosos podem trazer consequências que colocam em risco as gerações presentes no momento do acidente, bem como as futuras (OLIVEIRA, 2011, p.50).

Acidentes envolvendo vazamentos / derramamentos de substâncias perigosas são causados principalmente por falhas em equipamentos (tubulações) ou a má utilização. O dano à saúde está associado a queimaduras causadas devido às características causticas dos vapores, líquidos ou em soluções, além de ser tóxico por respiração (OLIVEIRA, 2011, p.50,51).

Assim, a análise de riscos envolve a identificação da avaliação, gerenciamento e comunicação dos eventos de risco ao meio ambiente e à saúde humana, para facilitar a previsão de ferramentas eficientes de ação frente aos possíveis acontecimentos ambientalmente danosos, a fim de minimizar seu impacto quando tal evento ocorrer.

Em uma avaliação criteriosa, Cozza (2013) afirma que na elaboração de um empreendimento é essencial a análise de risco que tem como foco a preparação do empreendimento a eventos imprevistos. Prever impactos que podem causar danos nas áreas circunvizinhas à sua instalação, por exemplo, é uma preocupação que deve ser analisada nas fases iniciais do projeto de tal organização.
Assim, tendo como foco a preservação do ambiente e a saúde humana, o presente trabalho analisa qualitativamente as ferramentas mais utilizadas na identificação e avaliação de riscos, bem como dos aspectos de gestão de riscos, em função da exigência legal e dos retornos socioambiental e financeiro para a sociedade civil.

\section{3 - Materiais e métodos}

A análise de risco pode ser aplicada a uma atividade proposta ou existente, que constitui em conjuntos de métodos e técnica identificando e avaliando, de forma qualitativa e quantitativa, tanto a organização empresarial como ambiente e as pessoas ao redor do empreendimento. Os resultados da análise vão desde a identificação de perigo, acidente, frequências esperadas e a magnitude das consequências (impactos) (COZZA, 2013, p.7).

Para a validação do estudo, quanto ao uso das ferramentas de análise de risco para decisão, foi aplicado um diagnóstico situacional em uma operação que utiliza substâncias perigosas no processo produtivo. $\mathrm{O}$ diagnóstico tem por caracterização visualizar pontos falhos na organização, quanto à segurança e aos procedimentos do dia-a-dia, para a criação de oportunidades de melhoria com 0 uso de ferramentas de análise de risco.

A Revisão de literatura é levantada utilizando palavras-chaves combinadas: "risco" and "substância perigosa" and "segurança" and "mitigação" and "preparação" and "ferramenta"; para a orientação do uso das ferramentas de análise de risco. A base para a pesquisa sistemática foi a Web of Science e a Science Direct.

Pela análise de literatura, e cinco ferramentas são selecionadas para teste com base nas características de preservação e proteção do ambiente e da saúde humana.

\section{4- Resultados e discussão}

Pela verificação das características da substância perigosa no diagnóstico situacional, é possível verificar a efetividade das ferramentas de análise de riscos e avaliar o grau de minimização do impacto de evento acidental.

Compreender o comportamento dos impactos sobre o ambiente quando tal evento de risco

www.uniube.br/entec - UNIUBE Campus Aeroporto - Uberaba/MG 
8ํㅡㄹ EnTec - Encontro de Tecnologia da UNIUBE / 28 a 30 de outubro de 2014

acontece e verificar as formas de mitigação deste eventos são testados nas ferramentas selecionadas.

A primeira ferramenta analisada é o Failure Mode and Effect Analysis (FMEA). Uma técnica para analisar falhas de projeto e aplicada com foco na diminuição das falhas potenciais. A proposta da ferramenta no estudo é direcionada na minimização da probabilidade de falha em nível confiável. A segunda ferramenta proposta é a Análise Preliminar de Risco como ferramenta de revisão geral de segurança nos sistemas para revelar aspectos que podem passar despercebidos aos gestores. (CESSARO, 2013, p.23).

O Hazard and Operability Study (HAZOP) é a técnica mais abrangente e usada na literatura, sendo esta a terceira ferramenta proposta no estudo para a identificação de risco visando a redução e a minimização de falhas operacionais nas instalações físicas.

A análise What If é utilizada como revisão do processo desde os materiais primários até o produto final. Sugerida como a quarta ferramenta de análise, seu uso é sugerido como investigador da causa raiz nos efeitos de falhas de determinadas componentes ou erros no processo (PARDO, 2009, p.59).

Considerada como a quinta proposta de uso na investigação de riscos e perigos para a organização que atua com substancia perigosa, o Check List é usado para se avaliar o estado do sistema ou da operação para assegurar conformidade aos padrões. Na proposta do uso do check list, é considerado a aplicação em conjunto com a ferramenta what if para melhor especificar causas e reduzir desperdícios de tempo.

\section{5 - Considerações finais}

O estudo buscou as técnicas mais utilizadas nos estudos de Análise de Risco, sendo possível verificar a efetividade das ferramentas de análise de riscos e avaliar o grau de minimização do impacto de evento acidental.

Uma vez aplicada as ferramentas e terem sido realizadas as avaliações de riscos, isso permite intervenções nos processos industriais mais seguras, garantindo assim, melhor segurança para os funcionários e comunidade e consequentemente diminuindo as chances de um acidente ambiental.

É importante ressaltar que, o cumprimento dos padrões de execução associados às intervenções que visam a preparação e a mitigação só serão estabelecidos quando executado por todos, sendo, imprescindível um bom treinamento a fim de conhecer cada processo de forma detalhada, e a educação buscando não só a preservação do ambiente como também visando a saúde humana.

\section{6 - Referências}

BRASIL, 2012. Ministério do Meio Ambiente. Conselho Nacional de Meio Ambiente, CONAMA. Resolução CONAMA 01/86. Disponível em: http://www.mma.gov.br/port/conama/res/res86/res 0186.html

CESARO, Lenice Raquel de. Adaptação das técnicas APR e HAZOP ao sistema de gestão de segurança do trabalho e meio ambiente. 2013. Tese (Especialização) - Especialização em Segurança do Trabalho, Universidade Tecnológica Federal do Paraná, Curitiba, 2013.

COZZA, Elison Fernandes. Análise de riscos. $1^{\circ} \mathrm{ed}$. Uberaba: Universidade de Ubera-ba, 2013.

OLIVEIRA, Wanderley Valério de. Acidentes com produtos perigosos no Estado de Goiás: evolução e causas. 2011. Tese (Mestrado) Programa de Mestrado em Ecologia e Produção Sustentável, Pontifícia Universidade Católica de Goiás, Goiânia, 2011.

PARDO, Johanna Andrea Rodrígues. Metodologia para análise e gestão de risco em projetos de pavimentos ferroviários. 2009. Tese (Mestrado) - Programa de Pós-Graduação em Geotecnia da UFOP, Universidade Federal de Ouro Preto, Ouro Preto, 2009.

PINHEIRO JUNIOR, João Gualberto. Aspectos jurídicos da análise de risco no processo de avaliação de impactos ambientais. MAIA (Manual de Avaliação do Impacto Ambiental) 0670. São Paulo, 1993. p. 1-2.

\section{Agradecimentos}

Ao curso de Engenharia Ambiental da Universidade de Uberaba que apoia 0 desenvolvimento de grupos de estudos e de pesquisa para 0 desenvolvimento de novas ferramentas e tecnologias. Ao Professor-orientador deste estudo, Leandro de Oliveira, pela disponibilidade e entusiasmo. 